\title{
The case number 130 of Townes Brocks syndrome
}

\author{
Aamir Jalal Al Mosawi ${ }^{1,2 *}$ \\ ${ }^{1}$ Advisor in Pediatrics and Pediatric Psychiatry, Children Teaching Hospital of Baghdad Medical City, Iraq \\ ${ }^{2}$ Head, Iraq Headquarter of Copernicus Scientists International Panel, Baghdad, Iraq
}

\begin{abstract}
Townes Brocks syndrome is a very rare genetic syndrome with 129 well-documented patients reported in the medical literature.

Townes Brocks syndrome has not been reported before in Iraq. The main aim of this book is to describe the first case of this syndrome in Iraq which seems to be the case number 130 .
\end{abstract}

\section{Introduction}

Townes Brocks syndrome is a rare autosomal dominant hereditary disorder which was probably first described in 1972 by Dr Philip L. Townes and Dr Eric Brocks. Dr Philip was professor of pediatrics at the University of Rochester, and Eric Brocks was a medical student. The syndrome is characterized by a triad of imperforate anus, limb defects, and ear abnormalities [1,2].

\section{Main features of the disorder include [1,2]:}

Anorectal malformations including imperforate anus (absence of an anal opening), recto-vaginal fistula, anal stenosis, unusually placed anus.

Hand and foot abnormalities including hypoplastic thumbs, fingerlike thumbs, syndactyly (webbed fingers/toes), fusion of the wrist bones, overlapping foot and/or toe bones.

Abnormalities of the ears with sensori-neural or conductive hearing impairment or loss or deafness.

Other organ abnormalities including hypoplastic kidneys, multicystic kidneys, dysplastic kidneys, and congenital heart defects such $\mathrm{s}$ tetralogy of Fallot and defects of the ventricular septum.

The main aim of this book is to describe the first case of this syndrome in Iraq which seems to be the case number 130 .

\section{Case report}

R.J was first seen at about the age of four months during November, 2018 because of poor feeding, failure to thrive, poor response to sounds, and poor head control. The girl also had low set ears, and deformity of the right foot with the presence of only three toes. There was no obvious abnormality of left foot, but the big toe was relatively large (Figure 1).

She was delivered at 38 weeks by cesarean section. She didn't pass motion and was found to have imperforated anus. She had colostomy, and the surgeon reported that the sigmoid was not present. The five centimeter colon ended at the pelvis, and cecum found on the left side. Cloaca treated with diversion colostomy.

The parents were relatives and have three normal children.

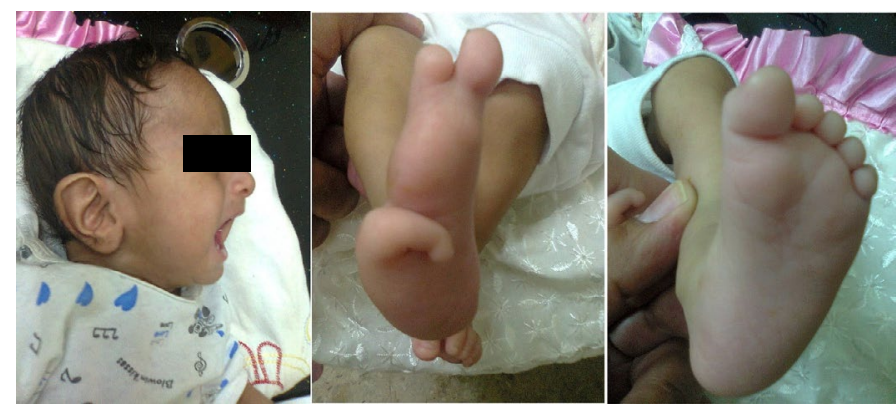

Figure 1. The girl had low set ears and deformity of the right foot with the presence of only three toes. There was no obvious abnormality of left foot, but the big toe was relatively large

Echocardiography performed during the first month showed normal findings.

Brain ultrasound performed on the fifth of August, 2018 showed normal findings. Abdominal ultrasound was also performed on the fifth of August, 2018, and showed small hypoplastic right kidney (18 $\mathrm{x} 12 \mathrm{~mm}$ ) with normal shape. At the age of forty-six days (16, August, 2018), an abdominal ultrasound showed small hypoplastic right kidney. The left kidney had normal size.

\section{Discussion}

Authors from Germany, the Netherlands, the UK, the USA, Belgium, Italy, Switzerland and the Czech republic defined Townes Brocks syndrome as a rare autosomal dominant malformation syndrome with a combination of anal, renal, limb and ear anomalies. Townes Brocks syndrome is a very rare genetic syndrome with 129 well-documented patients reported in the medical literature $[1,2]$. In

${ }^{\star}$ Correspondence to: Aamir Jalal Al Mosawi, Advisor in Pediatrics and Pediatric Psychiatry, Children Teaching Hospital of Baghdad Medical City, Iraq, E-mail: almosawiAJ@yahoo.com

Key words: townes Brocks syndrome, Iraq

Received: October 31, 2019; Accepted: November 19, 2019; Published: November 20, 2019 
this paper the first case of this syndrome in Iraq is reported which is the case number 130 .

\section{Acknowledgement}

The author would to express his gratitude for the parents of the patient who accepted publishing her photos.

\section{References}

1. Townes PL, Brocks ER (1972) Hereditary syndrome of imperforate anus with hand foot, and ear anomalies. J Pediat 81: 321-326.

2. Al-Mosawi AJ (2018) Townes Brocks syndrome. (1 $1^{\text {st }}$ Edn) LAP Lambert Academic Publishing, Saarbrücken.

Copyright: (C2019 Mosawi AJA. This is an open-access article distributed under the terms of the Creative Commons Attribution License, which permits unrestricted use, distribution, and reproduction in any medium, provided the original author and source are credited. 